\title{
Building moisture diagnosis: Processing, assessing and representation of environmental data for root cause analysis of mould growth
}

\author{
Paula Lopez-Arce ${ }^{1,2}(\bowtie)$, Hector Altamirano-Medina ${ }^{2}$, James Berry ${ }^{1}$, Dimitrios Rovas ${ }^{2}$, Fernando Sarce ${ }^{3}$, \\ Steve Hodgson ${ }^{1}$ \\ 1. Property Care Association, Huntingdon, Cambridgeshire, UK \\ 2. Institute for Environmental Design and Engineering, University College London, UK \\ 3. Facultad de Arquitectura y Construcción, Universidad Autónoma de Chile, Sede Temuco, Región de La Araucanía, Chile
}

\begin{abstract}
The occurrence of surface condensation and mould can lead to concerns of poor indoor air quality and adverse health implications of occupants. Remedial actions require identification of the root causes, but this can be challenging even for experts. The focus of the research is the development of a diagnostic tool that helps to streamline root cause analysis. The diagnostic method comprises a protocol with guidelines for installation of sensors, easy data collection, and a set of calculations to process environmental information. Environmental parameters collected and calculated from an environmental monitoring exercise of dwellings with and without mould, include physical properties associated with the indoor surface of external walls and surrounding air conditions. The methodology relies on linking specific surface and air environmental parameters together with critical thresholds proposed for the control and avoidance of surface condensation and mould growth in dwellings. These parameters were assessed and used to determine the likely causal factors of a moisture imbalanced environment leading to surface condensation and mould growth; poor thermal building envelope performance, an imbalanced heat-moisture regime, and/or insufficient ventilation. Examples from different scenarios are presented to show the process towards environmental data collection, post-processing to compute and assess pertinent parameters, and the display of environmental conditions in a clear and easy-to-interpret manner. The novel developed system is a time-saving method for processing and represents environmental data. It provides a straightforward building moisture index (BMI) and a systematic diagnostic procedure for environmental assessment and possible causes of mould growth. This helps to support neutral decision making to identify rectification strategies and direct to more cost-efficient solutions to existing damp and mould problems in buildings.
\end{abstract}

\author{
Keywords \\ diagnosis, \\ moisture, \\ condensation, \\ mould growth, \\ buildings, \\ environmental monitoring
}

\section{Article History}

Received: 29 November 2019

Revised: 05 June 2020

Accepted: 18 June 2020

(c) Author(s) 2020

\section{Introduction}

High levels of indoor atmospheric moisture can lead to surface condensation and mould growth that can be harmful to occupant health (Bornehag et al. 2004; Mendell et al. 2018). Dampness and mould have been reported to affect between $15 \%$ and $30 \%$ of European homes (Bonnefoy et al. 2003; Adan and Samson 2011). In the UK, mould growth has been associated with low indoor temperatures, high indoor humidity, and high occupancy density. Over the last decades mould issues in residential buildings have been increasing (Woolliscroft 1997; Rottier 2019). This problem is not just typical of cold or temperate West-European climates, since they may also be found in hot and high humidity or tropical areas (You et al. 2017; Udawatthaa et al. 2018). The combination of inadequate ventilation, irregular heating, poor thermal properties of external walls and high moisture generation (by breathing, showers, washing, cooking and drying clothes indoor, etc.) have been shown to increase the risk of moisture-related problems including mould,

E-mail: p.lopez-arce@ucl.ac.uk; paula@property-care.org 


\begin{tabular}{|c|c|c|c|}
\hline$a_{\mathrm{w}}$ & water activity $[-]$ & $R H i_{\text {air }}$ & indoor air relative humidity [\%] \\
\hline$B M I$ & Building Moisture Index $[-]$ & $R H o_{\text {air }}$ & outdoor air relative humidity [\%] \\
\hline$f R_{\mathrm{si}}$ & temperature factor $[-]$ & $T i_{\text {air }}$ & indoor air temperature $\left[{ }^{\circ} \mathrm{C}\right]$ \\
\hline $\mathrm{Po}_{\mathrm{v}}$ & outdoor partial water vapour pressure $[\mathrm{kPa}]$ & $T i_{\text {surf }}$ & indoor surface temperature $\left[{ }^{\circ} \mathrm{C}\right]$ \\
\hline$P i_{\mathrm{v}}$ & indoor partial water vapour pressure [kPa] & $T o_{\text {air }}$ & outdoor air temperature $\left[{ }^{\circ} \mathrm{C}\right]$ \\
\hline$P_{\text {vsat }}$ & saturation vapour pressure $[\mathrm{kPa}]$ & $V P E$ & vapour pressure excess $[\mathrm{kPa}]$ \\
\hline
\end{tabular}

condensation and dust mites. Small home volume spaces with higher levels of occupation, coupled with contemporary live styles (longer hours spent at home, a greater number of baths or showers and laundries per day compared to past times) is affecting the capacity of the buildings to buffering atmospheric moisture effectively (Hodgson 2018).

Many houses are poorly ventilated, resulting in the inadequate removal of excess moisture. Bathroom and kitchen exhaust fans in many properties do not work correctly; e.g. some do not have fans, and some are not used simply because they are too noisy.

Inadequate mechanical and natural ventilation, along with lack or intermittent heating (e.g. fuel poverty) generate the perfect conditions for the development of mould growth on indoor surfaces of exterior walls, such as those caused by missing insulation or presence of thermal bridges (local areas that are cooler or poorly insulated).

Identifying the causes associated to mould growth and taking correct remedial actions can be essential in reducing the prevalence of this problem. The interest for healthier and moisture-balanced indoor environments has sparked an increased demand to find effective methods to avoid inaccurate and expensive interventions or solving disrepair claim conflicts (Rose and Francisco 2004; Altamirano-Medina et al. 2009; Tsongas 2009; Rudert and Portnoy 2017; Mendell et al. 2018).

Under the UK government's new Homes (Fitness for Human Habitation) Act 2018, both private and social renters can take landlords to court and get compensation if they fail to sort out a range of related damp issues in the property. The new Act adds damp and mould growth, excess cold and excess heat, hazards listed in the Housing Act (2004) as factors to be considered when assessing whether a property is fit for human habitation. Occupants should be responsible for the appropriate use of the heating and ventilation systems while homeowners should be responsible for their proper function and efficacy (WHO 2018). It is the responsibility of the occupant taking precautions to prevent mould growth, and education and guidance on this matter should be provided (PCA 2018). However, the homeowner must eradicate the problem and tenants should get the work done and ask for indemnity if the damp issue is not solved (Tsongas 2009; Homes Act 2018).

An impartial and robust diagnostic method, based on scientific principles, could support the interests of occupants, tenants, private or social homeowners (i.e. City Council, Housing Associations), insurance companies, constructors, surveyors or expert witnesses.

The term building diagnostic has come into frequent use. It has been considered in moisture investigations which include tests and measurements, the gathering of physical evidence, surveys of damage, and occupant questionnaires. The sources of moisture causing a problem must be identified before any attempt can be made to determine remedial actions (Trechsel and Vigener 2009).

Identifying ways to avoid moisture problems and mould growth in buildings has been the subject of many research studies. Still, in the literature, measured data from real buildings in service are rather scarce (Vinha et al. 2018). Studies based on physical surveys in dwellings provide a valuable insight into moisture generation, ventilation and internal temperature that might be contributing to the development of mould. Dampness is commonly assessed by inspection and questionnaires; which can be highly subjective and not necessarily provide the real cause of the problem (Rose and Francisco 2004). On the other hand, instantaneous measurements (snapshots) of indoor air humidity are often made without considering the large variation throughout the day and week (Gevin and Holme 2011). Nowadays trying to solve these moisture-related problems mostly focuses on non-standardised procedures, manual observations, and site visits. Evaluating the evidence can be prone to erroneous interpretations and can lead to costly and unnecessary interventions. Even though the need of accurate protocols for moisture problem assessment in dwellings has been identified (Tsongas 2009), an integrated methodology is still lacking.

There is an increasing need for simulation programs that respond to building environmental changes (Korjenic et al. 2010). Most mould prediction models consider the main influencing factors for mould growth, described above; however, they are based on either experiments or assumptions 
(Vereecken and Roels 2012; Vereecken et al. 2015a). A diagnostic method for the assessment of indoor atmospheric moisture based on data collection, environmental monitoring and accurate evaluation could also serve to support the development of mould prediction models.

Towards the development of a novel supportive diagnostic tool that provided an impartial diagnosis of moisture-related issues, an extensive monitoring exercise was undertaken involving the collection of environmental data from dwellings with and without mould issues. The purpose of this study was to generate a new method for processing environmental data collected from buildings, providing an accurate, quick assessment and an easy neutral representation of causes of mould growth. This novel and time-saving method provides a straightforward building moisture impact indicator. This is a means of measuring the impact of key environmental parameters and causal factors supporting the identification of the most likely causes of mould growth and a moisture imbalanced environment in buildings.

\section{Methodology}

\subsection{Selection of environmental parameters and critical} thresholds as diagnostic indicators

An extensive literature review that included scientific publications, standards and regulatory guidance was carried out to identify key environmental parameters and the corresponding existing critical thresholds for the control and avoidance of surface condensation and mould growth in dwellings. Based on the literature, critical thresholds were identified. This formed a starting point towards the assessment and fine-tuning of these thresholds using the monitoring study undertaken in dwellings with and without mould issues. The environmental parameters and ranges used as critical thresholds considered in the prevention of moisture-related issues are: $R H i_{\text {air: }}: 45-80 \%$; $\mathrm{Ti}_{\mathrm{air}}: 10-20^{\circ} \mathrm{C}$; $V P E: 0.6-0.9 \mathrm{kPa} ; a_{\mathrm{w}}: 0.65-0.9 ; f R_{\mathrm{si}}: 0.65-0.75$ (Hens 1992; Oreszczyn et al. 2006; Kalamees 2006; Tsongas 2009; ADF 2010; British Standard 2011, 2013; Adan and Samson 2011; Dedesko and Siegel 2015; Azevedo et al. 2015).

\subsection{Data collection}

\subsubsection{Monitoring of indoor and outdoor environmental conditions}

Fifty properties, including flats, bungalows, semi-detached, detached and terraced houses from different UK regions, were monitored during two consecutive heating seasons (i.e. two winters). Half of them had previously reported visible condensation and/or mould growth issues, whereas the other half did not present any problems.

Rooms, including bedrooms, living rooms, halls, bathrooms and kitchens, were included in the monitoring exercise. Environmental sensors Lascar EL-USB-2 were used to record ambient air $T$ and $R H$. Outdoor sensors were placed in open areas protected from sun rays and rain. Indoor sensors were placed away from external walls, air currents, heating sources and direct sunlight. Indoor surface temperatures were measured on wall surfaces affected by mould using Lascar EL-USB-TC-T-type sensors (Figure 1). All these environmental parameters were collected every 30 min for 2 and 4 weeks. In dwellings without visible mould, the surface temperature sensors were placed on wall surfaces of rooms with high potential to develop mould (such as north facing rooms, with high occupancy or located close to high water vapour production rooms as bathrooms, e.g. master bedrooms). The selection of those spots to place the surface sensors was supported by infra-red thermal images to detect thermal bridges where mould could potentially grow.

The collected data ( $T$ and $R H$ ) was then used for the calculations of environmental parameters (e.g. water activity,
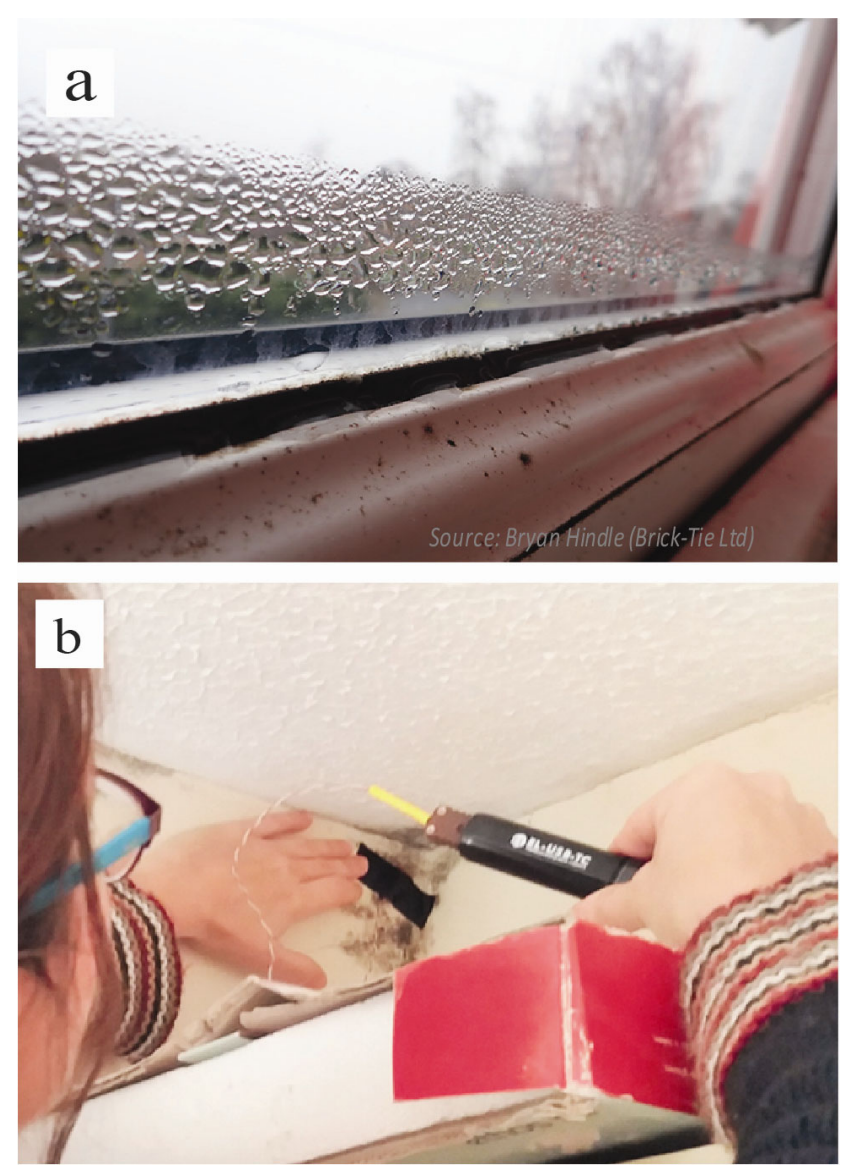

Fig. 1 Moisture related issues in some of the monitored dwellings: (a) condensation drops on glass and mould spots on window frame; (b) installation of surface temperature sensor onto mould surface 
$a_{\mathrm{w}}$ ), which were used to represent: (i) the thermal performance of the building fabric of each property, expressed as temperature factor (Eq. (1)); (ii) surface $R H$, expressed as water activity (Eq. (2)); (iii) heating-moisture regime, as a function of air $T$ and $R H$; and ventilation represented by indoors and outdoors air exchange, through vapour pressure differentials or water VPE (Eq. (3)):

$f R_{\mathrm{si}}=\left(T i_{\text {surf }}-T o_{\text {air }}\right) /\left(T i_{\text {air }}-T o_{\text {air }}\right)$

$a_{\mathrm{w}}=P i_{\mathrm{v}} / P_{\mathrm{vsat}} \quad$ or $R H($ surface $) / 100 \%$

$V P E=P i_{\mathrm{v}}-P o_{\mathrm{v}}$

The results were standardized for external reference conditions of $5{ }^{\circ} \mathrm{C}$ temperature and $80 \% R H$ (Oreszczyn et al. 2006).

\subsubsection{Building surveys}

A building survey was used for the collection of the following specific information: (i) history on the number and type of room affected by surface condensation and/or mould and location of these issues; (ii) floor plans; (iii) building characteristics (e.g. age, typology, dwelling's size, orientation, building materials, type of walls and floors), glazing and provision of ventilation (e.g. trickle vents, doors under-cut, extraction fans, location, etc.) and heating system. This information was used to support the development and verification of the moisture impact indicator.

\subsection{Building Moisture Index (BMI)}

The monitored data (e.g. surface temperatures), were used to compute key parameters e.g. water activity. These are subsequently used to define the Building Moisture Index $(B M I)$ which helps quantify the influence of the various parameters. The BMI helps in the identification of the most likely cause/s associated with mould growth in the studied properties. The $B M I$ is based on the ratios calculated for each parameter analysed using the data monitored in the dwellings during a minimum period of two weeks every $30 \mathrm{~min}$. These ratios refer to:

- The relationship between the values monitored and those that exceed the thresholds defined for each compute parameter (as total data percentage, i.e. time).

- Weighted values that establish the severity and likelihood of the event. These consider the previously calculated ratios in a scale that goes from high to medium and low.

The $B M I$ indicates whether the moisture environment is balanced or imbalanced based on the severity or likelihood of surface condensation and or mould growth according to an impact score. This is assigned to a causal factor and related calculated environmental parameters, as follows, BMI impact score: No Impact, NI-0-; Very Low, VL-1-; Low, L-2-; Moderate, M-3-; High, H-4-; Very High, VH-5-; Extremely High, EH-6-.

Condensation and/or mould growth may happen when there is an imbalance in the building moisture environment. This can occur due to the inadequate function of the following key causal factors:

- The building envelope performance (BMI-E), as a whole and/or related to the presence of thermal bridges (i.e. cold spots/low $T i_{\text {surf }}$ ), which relate to low $f R_{\text {si }}$ (poor thermal behaviour), and high $a_{\mathrm{w}}$ (surface $R H$ ) on wall/ceiling.

- The heat-moisture regimes (BMI-H), related to $T i_{\text {air }}$ and $R H i_{\text {air: }}$ :

- Low $T i_{\text {air }}$ caused by insufficient heating, heat loss and/or infiltrations (e.g. cold air entry through gaps) and around thermal bridges (cold environment)

- High atmospheric moisture levels of $R H i_{\text {air }}$

- The ventilation (BMI-V), related to high VPE through indoor-outdoor water vapour pressure differentials (insufficient/inefficient air exchange).

The extent of the impact created by the individual causal factors has been formulated based on the moisture impact indicator applied to both single and combined calculated environmental parameters. Finally, the blended impact of the various causal factors is expressed as a total BMI numerical indicator (BMI-T).

\subsection{Application of the moisture building diagnosis method and BMI indicator}

Three examples of building moisture diagnosis are described summarising the results of environmental monitoring performed in three UK dwellings. One of them is a representative case study of a property previously considered as not having visual surface condensation or mould growth issues (P1-NM). The second case represents a property with the aforementioned moisture-related issues (P2-M). A third example is presented for a dwelling with previous enquiries of mould issues (P3-M). In this latter property the diagnosis has been performed before and after taking the inferred remediation action; in this case related to a failure in the ventilation regime.

\section{Results and discussion}

\subsection{Environmental monitoring data}

The data obtained from the monitoring exercise shows distinct differences between dwellings with and without mould. Most of the environmental parameters recorded and calculated are closer or exceeding the threshold values considered as critical in standards and guidance (Table 1). 
Table 1 Environmental parameters obtained in fifty UK dwellings

\begin{tabular}{ccccccccc}
\hline & & $T_{\text {surface }}\left({ }^{\circ} \mathrm{C}\right)$ & $a_{\mathrm{w}}$ & $f R_{\mathrm{si}}$ & $T_{\text {indoor }}\left({ }^{\circ} \mathrm{C}\right)$ & $R H_{\text {indoor }}(\%)$ & $V P E(\mathrm{kPa})$ & $A M C\left(\mathrm{~g} / \mathrm{m}^{3}\right)$ \\
\hline \multirow{2}{*}{$\begin{array}{c}\text { Dwellings } \\
\text { with mould }\end{array}$} & MAX & 19.8 & 1.0 & 0.8 & 23.4 & 82.1 & 1.0 & 12.2 \\
& MIN & 10.2 & 0.7 & 0.4 & 13.7 & 54.3 & 0.2 & 6.9 \\
& Average & $14.9 \pm 2.4$ & $0.8 \pm 0.1$ & $0.7 \pm 0.1$ & $19.21 \pm 2.5$ & $67.7 \pm 6.86$ & $0.6 \pm 0.2$ & $9.8 \pm 1.3$ \\
\hline \multirow{2}{*}{$\begin{array}{c}\text { Dwellings } \\
\text { without mould }\end{array}$} & MAX & 21.3 & 0.7 & 1.0 & 22.5 & 70.7 & 0.7 & 10.3 \\
& MIN & 9.6 & 0.4 & 0.6 & 10.0 & 35.1 & 0.0 & 5.6 \\
& Average & $16.7 \pm 2.8$ & $0.6 \pm 0.1$ & $0.8 \pm 0.1$ & $18.7 \pm 2.9$ & $56.5 \pm 8.7$ & $0.3 \pm 0.2$ & $8.0 \pm 1.1$ \\
\hline
\end{tabular}

The data obtained was used as a reference for the moisture impact indicator, which was identified to help in the diagnosis of mould growth.

Table 1 and Figure 2 show that water activity $\left(a_{\mathrm{w}}\right)$ values varied between 0.7 and 1.0 in rooms with mould, whereas dwellings without mould have all $a_{\mathrm{w}}$ values below 0.7 . Values above 0.7 at a wall surface are appropriate for the development of most mould species (Adan and Samson 2011; Flannigan and Miller 2011). Besides, dwellings with mould have $f R_{s}$ values between 0.4 and 0.8 , whereas in dwellings without mould, these values range between 0.6 and 1.0. The thermal quality of each building envelope element can be characterised by the temperature factor $\left(f R_{\mathrm{si}}\right)$ at the internal surface; values of 0.75 and higher are generally suggested for the avoidance of mould growth in UK dwellings (British Standard 2013). Indoor $T$ and $R H$, and $V P E$ are parameters that can reflect issues with the ventilation and moisture-heating regimes of a dwelling. In this case, most dwellings with mould have $V P E$ values above $0.6 \mathrm{kPa}$, whereas in non-mouldy dwellings, these values are mostly below $0.6 \mathrm{kPa}$. An indoor environment is considered high in moisture when the $V P E$ is $>0.6 \mathrm{kPa}$ (Oreszczyn et al. 2006; British Standard 2011). $R H i_{\text {air }}$ values range between $35 \%$ and $71 \%$ in dwellings without mould. The values are higher, between $54 \%$ and $82 \%$, in dwellings with mould. Air moisture content $(A M C)$ is also higher in mouldy dwellings. However, no large differences in $T i_{\text {air }}$ were found in the studied properties.

Most dwellings had intermittent ventilation systems (extraction fans) installed in bathrooms and kitchens. However, in many mouldy dwellings, such type of ventilation was absent or not functional, which may have resulted in inadequate removal of excess moisture, as it has previously been reported by other authors (Tsongas 2009).

\subsection{Moisture impact indicator assigned to dwellings}

Following analysis of the environmental monitoring data, a moisture impact indicator was derived from aggregating the impact of key environmental parameters of each dwelling (Table 2). A category of high (H), medium (M) or low (L) was given to the obtained values according to the threshold considered in Table 1 and data from the literature already mentioned in the methodology section.

A dwelling with mould should be theoretically an indoor
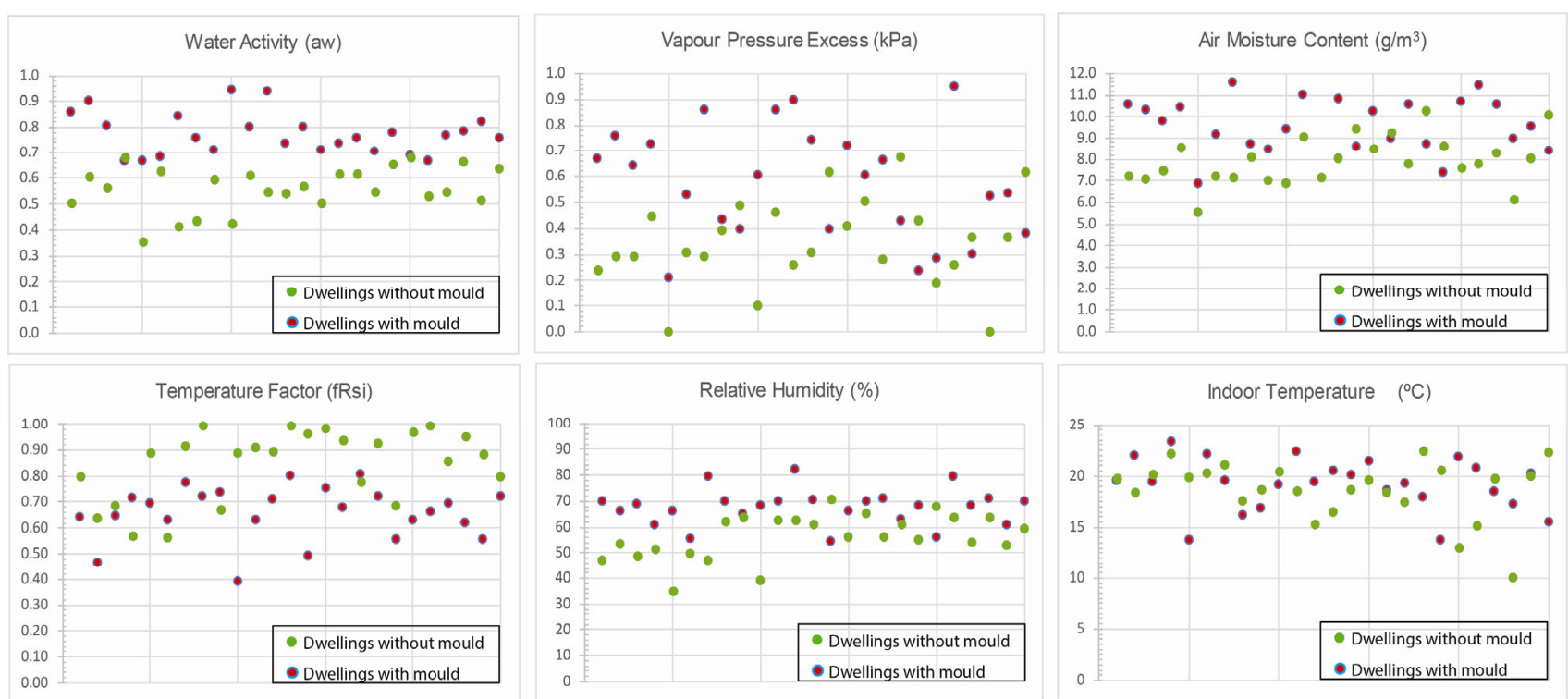

Fig. 2 Average values of the different environmental parameters obtained in UK dwellings monitored with and without condensation and/or mould issues 
Table 2 Rough moisture impact indicator (L: low; M: medium; H: high) assigned to the assessed parameters in UK dwellings

\begin{tabular}{|c|c|c|c|c|c|c|c|c|c|c|c|c|c|c|c|c|c|c|c|c|c|c|c|c|c|c|}
\hline \multirow[b]{2}{*}{ Exceed } & \multirow[b]{2}{*}{ Parameter } & \multicolumn{25}{|c|}{ Dwellings without Mould } \\
\hline & & 1 & 2 & 3 & 4 & 5 & 6 & 7 & 8 & 9 & 10 & 11 & 12 & 13 & 14 & 15 & 16 & 17 & 18 & 19 & 20 & 21 & 22 & 23 & 24 & 25 \\
\hline $\mathrm{L}$ & $a_{\mathrm{w}}$ & $\mathrm{L}$ & $\mathrm{L}$ & $\mathrm{L}$ & $\mathrm{L}$ & $\mathrm{L}$ & $\mathrm{L}$ & $\mathrm{L}$ & $\mathrm{L}$ & $\mathrm{L}$ & $\mathrm{L}$ & $\mathrm{L}$ & $\mathrm{L}$ & $\mathrm{L}$ & $\mathrm{L}$ & $\mathrm{L}$ & $\mathrm{L}$ & $\mathrm{L}$ & $\mathrm{L}$ & M & $\mathrm{L}$ & $\mathrm{L}$ & $\mathrm{L}$ & $\mathrm{L}$ & $\mathrm{L}$ & $\mathrm{L}$ \\
\hline $\mathrm{L}$ & $f R_{\mathrm{si}}$ & $\mathrm{L}$ & $\mathrm{H}$ & $\mathrm{H}$ & $\mathrm{H}$ & $\mathrm{L}$ & $\mathrm{H}$ & $\mathrm{L}$ & $\mathrm{L}$ & $\mathrm{H}$ & $\mathrm{L}$ & $\mathrm{L}$ & $\mathrm{L}$ & $\mathrm{L}$ & $\mathrm{L}$ & $\mathrm{L}$ & $\mathrm{L}$ & $\mathrm{H}$ & $\mathrm{L}$ & $\mathrm{H}$ & $\mathrm{L}$ & $\mathrm{L}$ & $\mathrm{L}$ & $\mathrm{L}$ & $\mathrm{L}$ & $\mathrm{H}$ \\
\hline $\mathrm{L}$ & $R H i_{\text {air }}$ & $\mathrm{L}$ & $\mathrm{L}$ & $\mathrm{L}$ & $\mathrm{L}$ & $\mathrm{L}$ & $\mathrm{L}$ & $\mathrm{L}$ & $\mathrm{L}$ & $\mathrm{L}$ & $\mathrm{L}$ & M & $\mathrm{L}$ & M & M & $\mathrm{L}$ & $\mathrm{H}$ & M & $\mathrm{L}$ & $\mathrm{L}$ & $\mathrm{H}$ & $\mathrm{H}$ & $\mathrm{L}$ & $\mathrm{H}$ & $\mathrm{L}$ & $\mathrm{L}$ \\
\hline $\mathrm{L}$ & $T i_{\text {air }}$ & $\mathrm{L}$ & M & $\mathrm{L}$ & $\mathrm{L}$ & $\mathrm{L}$ & $\mathrm{L}$ & $\mathrm{L}$ & M & $\mathrm{L}$ & $\mathrm{L}$ & $\mathrm{L}$ & $\mathrm{H}$ & M & $\mathrm{L}$ & $\mathrm{L}$ & $\mathrm{L}$ & M & $\mathrm{L}$ & $\mathrm{L}$ & $\mathrm{H}$ & $\mathrm{H}$ & $\mathrm{L}$ & $\mathrm{H}$ & $\mathrm{L}$ & $\mathrm{L}$ \\
\hline \multirow[t]{2}{*}{$\mathrm{L}$} & $V P E$ & $\mathrm{~L}$ & $\mathrm{~L}$ & $\mathrm{~L}$ & M & $\mathrm{L}$ & $\mathrm{L}$ & $\mathrm{L}$ & M & $\mathrm{L}$ & $\mathrm{L}$ & M & $\mathrm{L}$ & M & M & $\mathrm{M}$ & $\mathrm{L}$ & $\mathrm{L}$ & $\mathrm{H}$ & $\mathrm{M}$ & $\mathrm{L}$ & $\mathrm{L}$ & $\mathrm{L}$ & $\mathrm{L}$ & $\mathrm{L}$ & $\mathrm{M}$ \\
\hline & & \multicolumn{25}{|c|}{ Dwellings with Mould } \\
\hline Exceed & Parameter & 1 & 2 & 3 & 4 & 5 & 6 & 7 & 8 & 9 & 10 & 11 & 12 & 13 & 14 & 15 & 16 & 17 & 18 & 19 & 20 & 21 & 22 & 23 & 24 & 25 \\
\hline $\mathrm{H}$ & $a_{\mathrm{w}}$ & $\mathrm{H}$ & $\mathrm{H}$ & $\mathrm{H}$ & $\mathrm{L}$ & $\mathrm{L}$ & $\mathrm{L}$ & $\mathrm{H}$ & $\mathrm{H}$ & M & $\mathrm{H}$ & $\mathrm{H}$ & $\mathrm{H}$ & M & $\mathrm{H}$ & $\mathrm{H}$ & $\mathrm{H}$ & $\mathrm{H}$ & M & $\mathrm{H}$ & $\mathrm{L}$ & $\mathrm{L}$ & $\mathrm{H}$ & $\mathrm{L}$ & $\mathrm{H}$ & $\mathrm{M}$ \\
\hline $\mathrm{H}$ & $f R_{\mathrm{si}}$ & $\mathrm{H}$ & $\mathrm{H}$ & $\mathrm{H}$ & $\mathrm{H}$ & $\mathrm{H}$ & $\mathrm{H}$ & $\mathrm{H}$ & $\mathrm{H}$ & $\mathrm{H}$ & $\mathrm{H}$ & $\mathrm{H}$ & $\mathrm{H}$ & $\mathrm{H}$ & $\mathrm{H}$ & $\mathrm{H}$ & $\mathrm{H}$ & $\mathrm{L}$ & $\mathrm{H}$ & $\mathrm{H}$ & $\mathrm{H}$ & $\mathrm{L}$ & $\mathrm{H}$ & $\mathrm{L}$ & $\mathrm{H}$ & $\mathrm{H}$ \\
\hline $\mathrm{H}$ & $R H i_{\text {air }}$ & $\mathrm{H}$ & $\mathrm{L}$ & $\mathrm{H}$ & $\mathrm{L}$ & $\mathrm{L}$ & $\mathrm{L}$ & $\mathrm{H}$ & $\mathrm{H}$ & $\mathrm{M}$ & $\mathrm{M}$ & $\mathrm{M}$ & $\mathrm{H}$ & $\mathrm{H}$ & $\mathrm{L}$ & $\mathrm{M}$ & $\mathrm{M}$ & $\mathrm{H}$ & $\mathrm{M}$ & $\mathrm{H}$ & $\mathrm{M}$ & $\mathrm{H}$ & $\mathrm{H}$ & $\mathrm{H}$ & $\mathrm{L}$ & $\mathrm{H}$ \\
\hline $\mathrm{H}$ & $T i_{\text {air }}$ & $\mathrm{L}$ & $\mathrm{L}$ & $\mathrm{L}$ & $\mathrm{L}$ & $\mathrm{H}$ & $\mathrm{L}$ & $\mathrm{L}$ & $\mathrm{H}$ & $\mathrm{H}$ & $\mathrm{L}$ & $\mathrm{L}$ & $\mathrm{L}$ & $\mathrm{L}$ & $\mathrm{L}$ & $\mathrm{L}$ & $\mathrm{L}$ & $\mathrm{L}$ & $\mathrm{M}$ & $\mathrm{H}$ & $\mathrm{L}$ & $\mathrm{L}$ & $\mathrm{L}$ & $\mathrm{H}$ & $\mathrm{L}$ & $\mathrm{H}$ \\
\hline $\mathrm{H}$ & $V P E$ & $\mathrm{H}$ & $\mathrm{H}$ & $\mathrm{H}$ & $\mathrm{H}$ & $\mathrm{L}$ & $\mathrm{H}$ & $\mathrm{H}$ & $\mathrm{M}$ & $\mathrm{M}$ & $\mathrm{H}$ & $\mathrm{H}$ & $\mathrm{H}$ & $\mathrm{H}$ & $\mathrm{L}$ & $\mathrm{H}$ & $\mathrm{M}$ & $\mathrm{H}$ & $\mathrm{M}$ & $\mathrm{L}$ & $\mathrm{L}$ & $\mathrm{L}$ & $\mathrm{L}$ & $\mathrm{M}$ & $\mathrm{H}$ & $\mathrm{L}$ \\
\hline
\end{tabular}

moisture-imbalanced dwelling and should have internal conditions exceeding most of the thresholds defined. Whereas a dwelling without mould, one which is moisture-balanced, should show very few or no exceedances at all. As seen in Table 2, dwellings with mould are in general imbalanced, showing high $(\mathrm{H})$ exceedance in most of the parameters considered. On the contrary, dwellings without mould mostly have low (L) exceedance in relevant parameters.

\subsection{Application of the moisture building diagnosis method and BMI indicator reports}

Tables 3 and 4 compile the building features and average environmental conditions, respectively, of the three case studies collected during the two weeks of environmental monitoring. Figure 3 shows the results of the assessment and representation of environmental data in a dwelling without previously reported mould issues (P1-NM). The total Building Moisture Index (BMI) for this dwelling was found to be Low, with a total score of 2.3 BMI-T, which is representative of a balanced environment. The main dashboard (Figure 3(a)) shows the impact intensity of each causal factor that may lead to moisture-related issues. In this case, the heat-moisture regime and ventilation factors show Low impact (2.0 BMI-H) and Very Low impact (1.0 BMI-V), respectively. However, the apparent poor thermal envelope, with a High impact (4.0 BMI-E) might become an issue. As seen in Figure 3(b), most data fall into an area with critical $f R_{\mathrm{si}}$ values (or High and Extremely High likely poor thermal fabric), yet, with no critical $a_{\mathrm{w}}$ values (Low/Moderate degree of surface $R H$ ). Regarding the removal of the moisture produced (VPE values) in the dwelling, most data fall into a
Table 3 Building features of three UK dwellings (P1, P2 and P3), where the moisture building diagnosis and BMI have been applied

\begin{tabular}{lccc}
\hline \multirow{2}{*}{ Building feature } & P1-NM & P2-M & P3-M \\
\cline { 2 - 4 } Typology & Bungalow & Flat & Bungalow \\
\hline Year of construction & 1958 & 1960 & 1970 \\
\hline $\begin{array}{l}\text { Materials/external- } \\
\text { internal }\end{array}$ & $\begin{array}{c}\text { Bricks/plaster- } \\
\text { board }\end{array}$ & Bricks/rendered and plastered \\
\hline Walls & Cavity & Cavity & Cavity \\
\hline Floors & Suspended timber & Solid/suspended & Solid \\
\hline Ventilation system & $\begin{array}{c}\text { Extraction fan } \\
\text { (only kitchen) }\end{array}$ & No fans & $\begin{array}{c}\text { Intermittent } \\
\text { extraction } \\
\text { fans }\end{array}$ \\
\hline $\begin{array}{c}\text { Heating system } \\
\text { Gas central-radiators }\end{array}$ \\
\hline $\begin{array}{l}\text { Mould location/ } \\
\text { monitoring }\end{array}$ & $\begin{array}{c}\text { No mould/ } \\
\text { bedroom }\end{array}$ & Master bedroom & Wet room \\
\hline
\end{tabular}

NM: no mouldy; M: mouldy.

Table 4 Environmental conditions of three UK dwellings (P1, P2 and P3) where the moisture building diagnosis and BMI have been applied

\begin{tabular}{ccccccc}
\hline Dwelling & $\begin{array}{c}T i_{\text {surf }} \\
\left({ }^{\circ} \mathrm{C}\right)\end{array}$ & $\begin{array}{c}T i_{\text {air }} \\
\left({ }^{\circ} \mathrm{C}\right)\end{array}$ & $\begin{array}{c}R H i_{\text {air }} \\
(\%)\end{array}$ & $\begin{array}{c}V P E \\
(\mathrm{kPa})\end{array}$ & $a_{\mathrm{w}}$ & $f R_{\mathrm{si}}$ \\
\hline P1-NM & $13.1 \pm 2.1$ & $17.9 \pm 2.8$ & $44.2 \pm 3.5$ & $0.3 \pm 0.1$ & $0.60 \pm 0.0$ & $0.7 \pm 0.1$ \\
P2-M & $15.7 \pm 1.4$ & $19.6 \pm 1.8$ & $63.2 \pm 8.3$ & $0.9 \pm 0.2$ & $0.8 \pm 0.1$ & $0.8 \pm 0.1$ \\
P3-M- & $13.9 \pm 1.8$ & $19.2 \pm 1.57$ & $59.1 \pm 6.8$ & $0.7 \pm 0.2$ & $0.8 \pm 0.1$ & $0.7 \pm 0.1$ \\
Before & & & & & & \\
$\begin{array}{c}\text { P3-M- } \\
\text { After }\end{array}$ & $15.7 \pm 1.3$ & $18.9 \pm 1.4$ & $50.3 \pm 4.9$ & $0.4 \pm 0.2$ & $0.6 \pm 0.1$ & $0.8 \pm 0.1$ \\
\hline
\end{tabular}

*NM: no mouldy; M: mouldy; Before and After: before and after changing the ventilation system, respectively. 


\begin{tabular}{|c|c|c|c|c|c|c|c|c|}
\hline Root Cause of Mould growth & \multicolumn{8}{|c|}{ Building Moisture Index-BMI (Impact score:0-6) } \\
\hline \multirow[b]{2}{*}{ CAUSAL FACTORS / IMPACT } & $\mathrm{N}-\mathrm{O}$ & Vl:-1 & L.2 & M-3 & H. 4 & VH.5 & EHH 6 & \\
\hline & No Impact & Very Low & Low & Moderate & High & Very High & $\begin{array}{c}\text { Extremely } \\
\text { High }\end{array}$ & \\
\hline Poor ENVELLPE Performance & & & & & H & & & 4.0 \\
\hline Imbalance HEAT-MOSTURE Regime & & & $\mathrm{L}$ & & & & & 2.0 \\
\hline Insulficient VENTLATION Ratio & & VL & & & & & & 1.0 \\
\hline Total & & & L & & & & & 2.3 \\
\hline
\end{tabular}
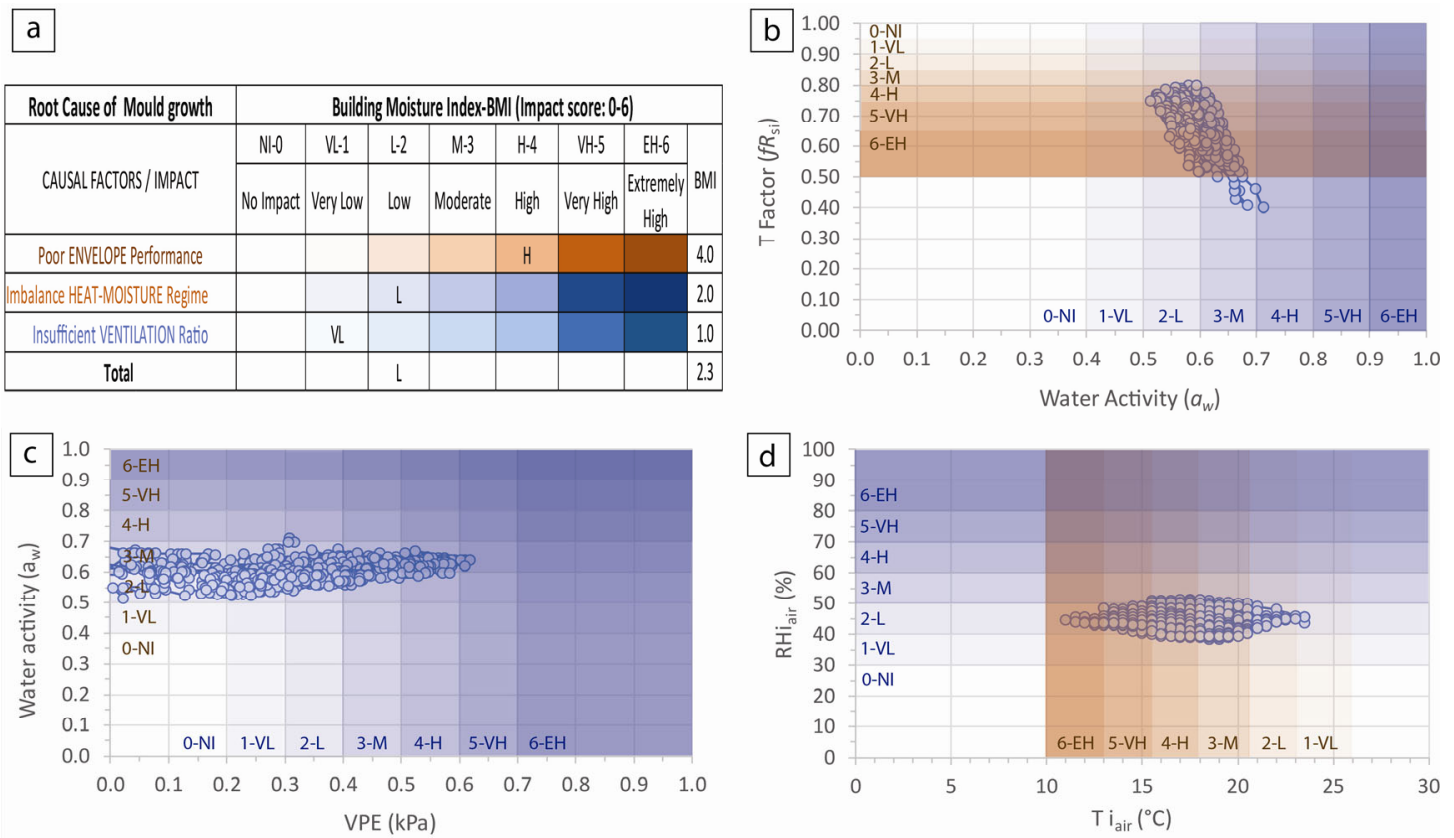

Fig. 3 Assessment and representation of environmental data collected in a dwelling (bedroom) without mould issues (P1-NM): (a) dashboard showing the impact scores of different causal factors leading to mould growth; (b) representation of parameters related to the envelope's performance; (c) graph showing parameters related to ventilation; (d) representation of parameters related to heat-moisture regime

zone that is representative of a dry environment, defined by No Impact/Very Low/Low impact of VPE (Figure 3(c)). As for the heat-moisture regime, most data fall into a zone that can be considered warm and comfortable, with Moderate/Vey Low average impact (Figure 3(d)).

On the contrary, Figure 4 shows the results from a dwelling with previously reported mould issues (P2-M). The total BMI indicates a Very High total score (4.5 BMI-T), representing a moisture imbalanced environment (Table 4). The dashboard (Figure 4(a)) shows the impact of each causal factor that might lead to moisture-related issues. The heat-moisture regime scored 3.0 BMI-H (Moderate impact), while both the ventilation and performance of the building envelope scored Extremely High (6.0 BMI-V) and Very High impact (4.5 BMI-E), respectively. Regarding the thermal quality of the envelope (Figure 4(b)), data falls into an area that can be considered appropriate from a $f R_{\text {si }}$ point of view, however also unsuitable when in conjunction of critical $a_{\mathrm{w}}$ values (High/Very High), which can lead to surface condensation and mould growth. The removal of the moisture produced in this dwelling seems to be a problem, with Extremely High VPE critical values (Figure 4(c)) in a warm but humid environment (Figure 4(d)).

Figure 5 shows an interesting case study that reflects the changes in the environmental conditions produced in a dwelling (P3-M) when accurate rectifications measurements are taken (Table 4). In this case, the intermittent extraction fan located in a wet room of a dwelling has been substituted by a continuously running exhaust fan with humidistat. The graphs show how the data fall in an area of environmental conditions prone to surface condensation and mould growth. This is inferred by the critical $a_{\mathrm{w}}$ and $f R_{\mathrm{si}}$ values obtained in this property during the two weeks before the installation of the new fan (Figure 5(a)). The data gathered at that time also shows a wet environment due to an inadequate ventilation system with Very/Extremely High VPE values (Figure 5(b)). The environmental conditions are improved after the change caused by setting up the new fan, creating a balanced moisture environment that has low chances of mould growth (Figures 5(a) and 5(c)). A less humid environment was generated as a result of moisture control through a better ventilation system (Figure 5(d)).

The innovative method developed shows the potential of a time and cost-saving tool able to process and accurately assess and represent environmental data rapidly. While mould prediction models aim to predict mould growth, our system is a method for data collection and analysis, which provides a diagnosis and a possible cause of mould growth. This can support decision-making on rectification problems related to high atmospheric moisture in residential buildings.

Vereecken et al. $(2015 \mathrm{a}, \mathrm{b})$ presented preliminary studies on the validity of mould prediction models frequently applied in building physics (e.g. VTT model, Sedlbauer's isopleths, biohygrothermal model). They found that although similar laboratory experiments serve as the input for the development of the prediction models, quite large discrepancies are observed 


\section{a}

\begin{tabular}{|c|c|c|c|c|c|c|c|c|}
\hline Root Cause of Mould growth & \multicolumn{8}{|c|}{ Building Moisture Index-BMI (Impact score: 0.6) } \\
\hline \multirow[b]{2}{*}{ CAUSAL FACTORS/IMPACT } & N.:O & V:-1 & 1.2 & M-3 & H.4 & VH-5 & EH- 6 & \\
\hline & No mpact & Very Low & Low & Moderate & High & Verytigh & $\begin{array}{c}\text { Extremely } \\
\text { High }\end{array}$ & BMI \\
\hline Poor ENVELDPE Performance & & & & & & VH & & 4.5 \\
\hline Imbalance HEAT-MOISTRRE Regime & & & & M & & & & 3.0 \\
\hline Insufficient VENTILATION Ratio & & & & & & & EH & 6.0 \\
\hline Total & & & & & & VH & & 4.5 \\
\hline
\end{tabular}
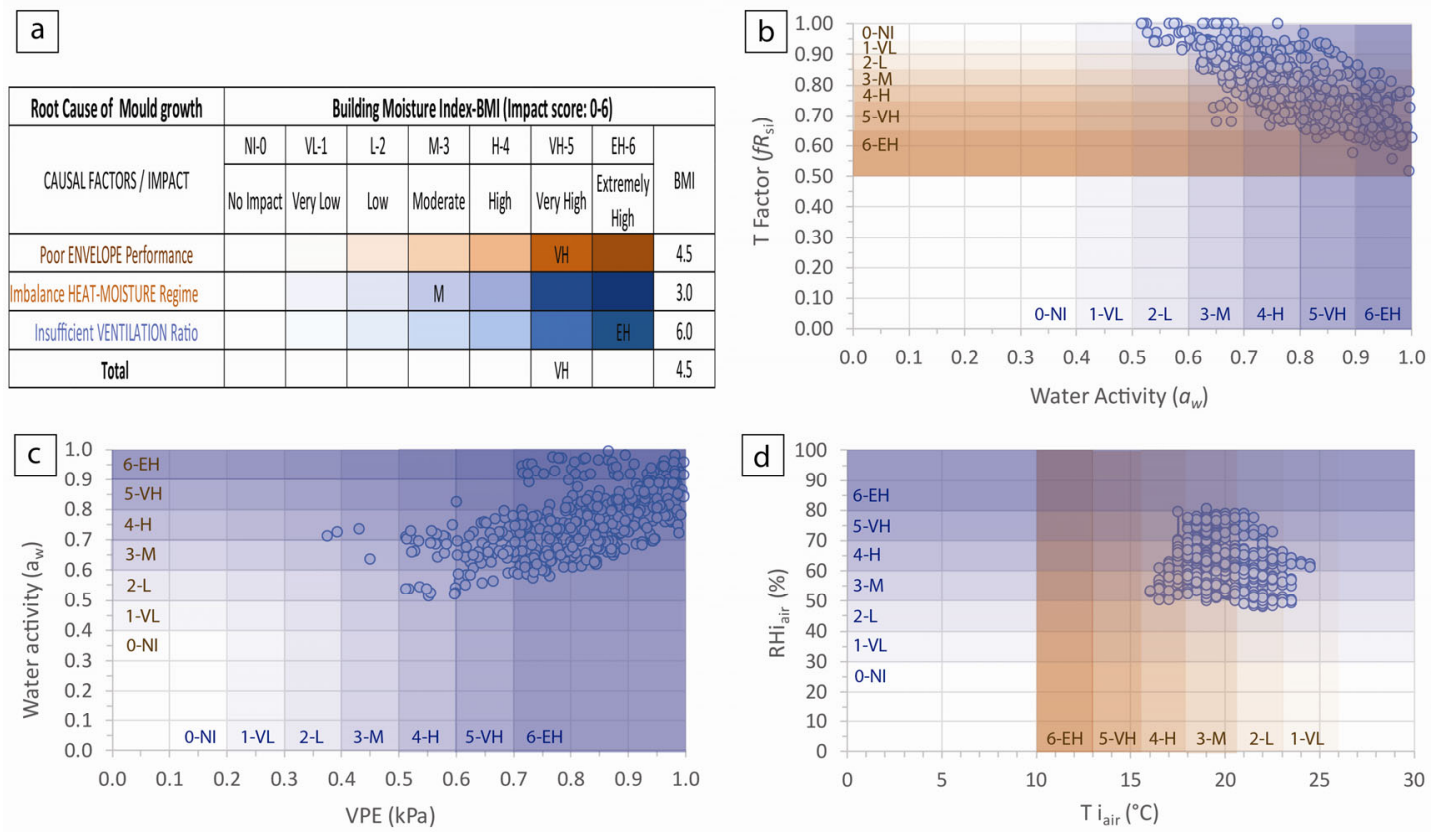

Fig. 4 Assessment and representation of environmental data collected in a dwelling (bedroom) with mould issues (P2-M): (a) dashboard showing the impact scores of different causal factors leading to mould growth; (b) representation of parameters related to the envelope's performance; (c) graph showing parameters related to ventilation; (d) representation of parameters related to heat-moisture regime
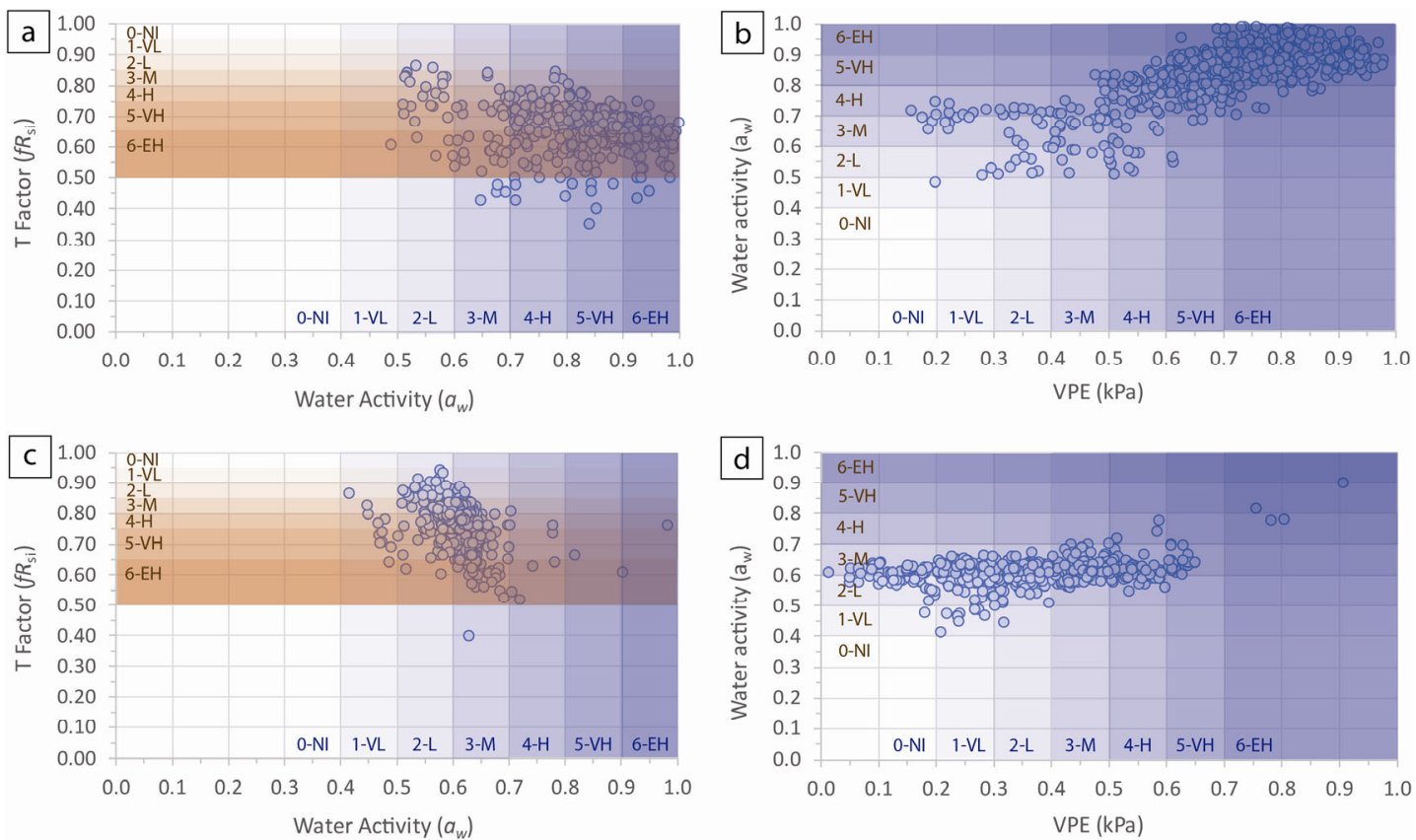

Fig. 5 Assessment and representation of environmental conditions in a bathroom of a UK dwelling with mould issues (P3-M) before and after changing the ventilation system (i.e. from intermittent extract fan to continuously running exhaust fan with humidistat): (a) parameters related to envelope's performance and (b) parameters related to ventilation ratio, before the change; (c) parameters related to envelope's performance and $(\mathrm{d})$ parameters related to ventilation ratio, after the change

among them. They have also identified that the collection of reliable data sets is essential for the validity of the models. It seems clear that using single models for mould and moisture risks predictions is a current challenge in the field of building physics being important, not limiting these just to deterministic approaches. Sensitivity analysis of the biodeterioration risks with probabilistic-based methodologies or stochastic models accounting for the associated uncertainties are necessary for providing a clear association of the microbial growth to its likelihood, enabling the identification and 
significance of the dominant parameters. This will deliver more comprehensive conclusions regarding the performance of constructions and the related building environment (Gradeci et al. 2018a,b).

We are presenting a descriptive moisture method based on environmental monitoring, real data collection, accurate calculations and assessment of environmental parameters linked to moisture-related issues. Previous research emphasized the importance of considering the variations of temperature and humidity and the duration of favourable and unfavourable conditions for mould growth (Johansson et al. 2013, Sadovský and Koronthályová 2017). Further development of this tool will consider these variables using other moisture criteria (e.g. according to ADF 2010), together with data analysis of time intervals and environmental fluctuations. This will allow a better understanding of the effects of environmental parameters on mould growth in the built environment.

\section{Conclusions}

The following conclusions can be drawn from this research project on residential atmospheric moisture diagnosis:

- A moisture balanced dwelling should have lower $a_{\mathrm{w}}, R H i_{\text {air }}$ and $V P E$ and higher $T i_{\text {air }}$ and $f R_{\mathrm{si}}$ values.

- The cause of mould growth may not be the result of just one parameter prompting the problem but a causal association between the different parameters. Mould growth could be an indication of an imbalanced dwelling, where a combination of parameters might be responsible for it.

- The higher the number of environmental parameters above or below certain thresholds could be indicative of a moisture imbalanced house, therefore the higher the likelihood of mould development, being $a_{\mathrm{w}}$ or VPE the most critical parameters. Values related to the thermal quality of the envelope $\left(f R_{\mathrm{si}}\right)$ can be less important if surface $R H\left(a_{\mathrm{w}}\right)$ and air exchange (VPE), do not exceed their corresponding established thresholds.

- The lower the thermal performance of the dwelling's envelope (low $f R_{\mathrm{si}}$ values, there high $a_{\mathrm{w}}$ ) and/or poor performance of the mechanical or natural ventilation (high VPE values), the higher the likelihood of developing mould growth by an excess of moisture production.

- Inadequate ventilation has been found as the primary cause leading to mould growth in most of the studied dwellings. This is reflected by an excess of VPE, that in many cases was also combined by poor thermal performance of the dwelling envelope, reflected by a low $f R_{\text {si. }}$.

- The proposed methodology based on data collection, postprocessing by linking key surface and air environmental parameters together with critical thresholds provides clear insights of the likely causes of mould growth.
This study shows that the causes of mould growth and the most appropriate and effective rectification strategies can accurately be determined using easily acquired environmental data taken from occupied buildings.

The novel data analysis developed is a time-saving method that provides a systematic diagnostic procedure to support neutral decision-making concerning mould growth, helping to identify rectification strategies and cost-efficient solutions.

The novelty BMI moisture diagnostic method developed is based on environmental monitoring, real data collection, accurate calculations and assessment of environmental parameters linked to moisture-related issues. This is also a system that might support the development and verification of mould prediction models.

\section{Acknowledgements}

This research has been supported by a Grant funded by the Technology Strategy Board and Engineering \& Physical Sciences Research Council (Innovate UK) and The Property Care Association (PCA) through a Knowledge Transfer Partnership (KTP) project (KTP010485) between University College London (UCL) and PCA. Special thanks go to all the PCA members that have contributed to the success of this research project.

Open Access: This article is licensed under a Creative Commons Attribution 4.0 International License, which permits use, sharing, adaptation, distribution and reproduction in any medium or format, as long as you give appropriate credit to the original author(s) and the source, provide a link to the Creative Commons licence, and indicate if changes were made.

The images or other third party material in this article are included in the article's Creative Commons licence, unless indicated otherwise in a credit line to the material. If material is not included in the article's Creative Commons licence and your intended use is not permitted by statutory regulation or exceeds the permitted use, you will need to obtain permission directly from the copyright holder.

To view a copy of this licence, visit http://creativecommons.org/licenses/by/4.0/.

\section{References}

Adan OC, Samson RA (2011). Fundamentals of mold growth in indoor environments and strategies for healthy living. Wageningen, The Netherlands: Wageningen Acadaemic Publishers.

ADF (2010). The Buildings Regulations Approved Document F: Ventilation. HM Government, NBS, RIBA Enterprises Ltd.

Altamirano-Medina H, Davies M, Ridley I, Mumovic D, Oreszczyn T (2009). Guidelines to avoid mould growth in buildings. Advances in Building Energy Research, 3: 221-235. 
Azevedo JA, Chapman L, Muller CL (2015). Critique and suggested modifications of the degree days methodology to enable long-term electricity consumption assessments: a case study in Birmingham, UK. Meteorological Applications, 22: 789-796.

Bonnefoy XR, Braubach M, Moissonnier B, Monolbaev K, Röbbel N (2003). Housing and health in Europe: preliminary results of a PanEuropean study. American Journal of Public Health, 93: 1559-1563.

Bornehag CG, Sundell J, Bonini S, Custovic A, Malmberg P, et al. (2004). Dampness in buildings as a risk factor for health effects, EUROEXPO: A multidisciplinary review of the literature (1998-2000) on dampness and mite exposure in buildings and health effects. Indoor Air, 14: 243-257.

British Standard (2011). BS EN ISO 5250:2011 + A1:2016. Code of practice for control of condensation in buildings. London: BSI

British Standard (2013). BS EN ISO 13788:2012. Hygrothermal performance of building components and building elements Internal surface temperature to avoid critical surface humidity and interstitial condensation. London: BSI

Dedesko S, Siegel JA (2015). Moisture parameters and fungal communities associated with gypsum drywall in buildings. Microbiome, 3: 71 .

Flannigan B, Miller JD (2011). Microbial growth in indoor environments. In: Flannigan B, Samson RA, Miller JD (eds), Microorganisms in Home and Indoor Work Environments: Diversity, Health Impacts, Investigations and Control. Boca Raton, FL, USA: CRC Press. pp 57-107.

Geving S, Holme J (2012). Mean and diurnal indoor air humidity loads in residential buildings. Journal of Building Physics, 35: 392-421.

Gradeci K, Berardi U, Time B, Köhler J (2018a). Evaluating highly insulated walls to withstand biodeterioration: A probabilistic-based methodology. Energy and Buildings, 177: 112-124.

Gradeci K, Labonnote N, Time B, Köhler J (2018b). A probabilisticbased methodology for predicting mould growth in façade constructions. Building and Environment, 128: 33-45.

Hens H (1992). IEA Annex 14: Condensation and energy. Journal of Thermal Insulation, 15: 261-273.

Hodgson S (2018). The changing nature of damp investigations and the implications of retrofit cavity and external wall insulation on standard forms of building. Journal of Building Survey, Appraisal and Valuation, 6: 301-311.

Homes Act (2018). Homes (Fitness for Human Habitations) Act 2018. In: Guidance for Tenants, Landlords and Local Authorities. Ministry of Housing, Communities \& Local Government. Available at https://www.gov.uk/government/publications/homes-fitness-forhuman-habitation-act-2018. Accessed 29 Mar 2019.

Housing Act (2004). Available at https://www.legislation.gov.uk/ukpga/ 2004/34/contents

Johansson P, Bok G, Ekstrand-Tobin A (2013). The effect of cyclic moisture and temperature on mould growth on wood compared to steady state conditions. Building and Environment, 65: 178-184.

Kalamees T (2006). Critical values for the temperature factor to assess thermal bridges. Proceedings of the Estonian Academy of Sciences. Engineering, 12: 218-229.

Korjenic A, Teblick H, Bednar T (2010). Increasing the indoor humidity levels in buildings with ventilation systems: Simulation aided design in case of passive houses. Building Simulation, 3: 295-310.

Mendell MJ, MacHer JM, Kumagai K (2018). Measured moisture in buildings and adverse health effects: A review. Indoor Air, 28: 488-499.

Oreszczyn T, Ridley I, Hong SH, Wilkinson P (2006). Mould and winter indoor relative humidity in low income households in England. Indoor and Built Environment, 15: 125-135.

PCA (2018). Condensation Guidelines. Huntingdon, UK: The Property Care Association.

Rose WB, Francisco PW (2004). Field evaluation of the moisture balance technique to characterize indoor wetness. In: Thermal Performance of Exterior Envelopes of Whole Buildings IX. Cambridge, UK: ASHRAE.

Rottier R (2019). English Housing Survey: Headline Report 2017-18. Housing and Planning Analysis Division. London: Ministry of Housing, Communities and local Government.

Rudert A, Portnoy J (2017). Mold allergy: is it real and what do we do about it? Expert Review of Clinical Immunology, 13: 823-835.

Sadovský Z, Koronthályová O (2017). Exploration of probabilistic mould growth assessment. Applied Mathematical Modelling, 42: 566-575.

Trechsel HR, Vigener NW (2009). Investigating moisture damage caused by building envelope problems. In: Trechsel HR, Bomberg MT (eds), Moisture Control in Buildings: The Key Factor in Mold Prevention, 2nd edn. West Conshohocken, PA, USA: ASTM International. pp 160-179.

Tsongas G (2009). Case Studies of Moisture Problems in Residences. In: Trechsel HR, Bomberg MT (eds), Moisture Control in Buildings: The Key Factor in Mold Prevention, 2nd edn. West Conshohocken, PA: ASTM International.

Udawattha C, Galkanda H, Ariyarathne IS, Jayasinghe GY, Halwatura $\mathrm{R}$ (2018). Mold growth and moss growth on tropical walls. Building and Environment, 137: 268-279.

Vereecken E, Roels S (2012). Review of mould prediction models and their influence on mould risk evaluation. Building and Environment, 51: 296-310.

Vereecken E, Vanoirbeek K, Roels S (2015a). Towards a more thoughtful use of mould prediction models: A critical view on experimental mould growth research. Journal of Building Physics, 39: 102-123.

Vereecken E, Vanoirbeek K, Roels S (2015b). A preliminary evaluation of mould prediction models based on laboratory experiments. Energy Procedia, 78: 1407-1412.

Vinha J, Salminen M, Salminen K, Kalamees T, Kurnitski J, Kiviste M (2018). Internal moisture excess of residential buildings in Finland. Journal of Building Physics, 42: 239-258.

WHO (2018). World health statistics 2018: Monitoring health for the SDGs, sustainable development goals. Geneva: World Health Organization.

Woolliscroft M (1997). Residential ventilation in the United Kingdom: An overview. ASHRAE Transactions: Symposia, 103(1): 706-716.

You S, Li W, Ye T, Hu F, Zheng W (2017). Study on moisture condensation on the interior surface of buildings in high humidity climate. Building and Environment, 125: 39-48. 